\title{
The burden of low back pain among undergraduate physiotherapy students at the University of Zimbabwe: a cross-sectional study
}

\author{
M. Chiwaridzo ${ }^{1 *} \mathbb{0}$, K. J. Chamarime ${ }^{2}$ and J. M. Dambi ${ }^{1}$
}

\begin{abstract}
Objective: Globally, non-specific low back pain (NSLBP) is a common cause of morbidity in all people including physiotherapy students. However, no study has investigated the problem among undergraduate physiotherapy students in Zimbabwe. This study was conducted, therefore, to provide evidence of the prevalence, clinical characteristics and consequences of recurrent NSLBP among undergraduate physiotherapy students at the University of Zimbabwe.

Results: The final sample had 90 participants, giving a study response rate of $97.8 \%$. The median age of the participants was 22 years. The lifetime prevalence of NSLBP was $56.7 \%(n=51)$ and the mean age of onset for NSLBP was 19.7 years ( $S D=1.64$ years). The 12-month prevalence of recurrent NSLBP was 38.9\% $(n=35)$. Of the 35, $20(57.1 \%)$ experienced at least three episodes in the last 12 months. Each episode lasted for 1-7 days in most participants $(n=31,88.6 \%)$. The mean intensity of recurrent episodes was $3.37(S D=1.43)$ measured on Visual Analogue Scale. Only 7 (20\%) experienced at least one functional limitation due to recurrent NSLBP. Additionally, only 2 (5.7\%) sought medical treatment for the pain. However, $6(17.1 \%)$ had to be absent from the university secondary to recurrent NSLBP.
\end{abstract}

Keywords: Physiotherapy, Low back pain, Zimbabwe

\section{Introduction}

Non-specific low back pain (NSLBP) is a major global burden indiscriminately affecting all people including physiotherapists [1-9]. Physiotherapists are at an increased risk of developing NSLBP due to the physical demands of the profession [7, 10-15]. This is despite physiotherapists having expert knowledge about injury prevention from training [16]. However, many physiotherapists report the first episodes of NSLBP during undergraduate training $[11,13,14]$. The possibility of university students being burdened with NSLBP before

\footnotetext{
*Correspondence: mchiwaridzo@medsch.uz.ac.zw

${ }^{1}$ Department of Rehabilitation, College of Health Sciences, University of Zimbabwe, Ground Floor, New Health Sciences Building, Avondale, Harare, Zimbabwe

Full list of author information is available at the end of the article
}

full-time employment is a cause of concern [3]. This is particularly so for physiotherapy students who are exposed to physical manual handling techniques during training and the risk factors for NSLB are likely to increase once the trainees qualify and assume full-time jobs which are more demanding [17].

Different studies have reported varying prevalence rates for NSLBP among physiotherapy students with lifetime prevalence figures ranging between 36 and 69\% $[7,10,12,17]$. Also, Nyland and Grimmer [12] reported a 12 -month prevalence of $63 \%$ in Australia. However, there is dearth of literature on the prevalence of NSLBP among undergraduate physiotherapy students from low-resourced settings like Zimbabwe. This is a significant shortcoming against the background of high prevalence of occupational-related NSLBP reported among 
Zimbabwean physiotherapists $[15,18]$. Unabated, NSLBP has been linked to reduced health-related quality of life, school absenteeism, increased health-seeking behaviour and use of pain medication [19, 20]. Therefore, research efforts investigating the prevalence, clinical characteristics and consequences of recurrent NSLBP among undergraduate physiotherapy students are warranted to understand the magnitude of the condition, its impact and possibly inform primary prevention programmes. This study sought to (i) to determine the lifetime and 12-month prevalence of recurrent NSLBP among undergraduate physiotherapy students, (ii) to describe the clinical characteristics of recurrent NSLBP and lastly, (iii) to determine the consequences of recurrent NSLBP.

\section{Main text}

\section{Study design, research setting and participants}

A cross-sectional descriptive study was conducted at UZ targeting all undergraduate physiotherapy students. UZ is the only university offering undergraduate training in physiotherapy in Zimbabwe. The following parameters were used to estimate sample size using EPI info StatCalc: (i) total population of physiotherapy students at UZ $(\mathrm{N}=92)$ (ii) expected 12-month prevalence for NSLBP of $32.5 \%$ [10], (iii) precision effect of 3\%, (iv) design effect of 1 . The minimum calculated sample size at $95 \%$ confidence interval was 84 students. All undergraduate physiotherapy students from first to final year were invited to participate. Physiotherapy is offered as a four-year long degree programme [21]. Exclusion from the study was based on students having a physical disability such as leg length discrepancy which is a known risk factor for low back pain [22].

\section{Survey instrument}

The study questionnaire was adopted from previous studies [23, 24]. Briefly, the first section elicited demographic and university-related information. Section B had questions on lifetime prevalence, age at onset for the first episode of NSLBP, and recurrent NSLBP. Subsequent questions elicited information on the clinical characteristics of recurrent NSLBP guided by the definition provided by Stanton et al. [25]. Additionally, the questionnaire asked about the consequences of recurrent NSLBP. Nine questions derived from the Hanover Low Back Pain Disability Questionnaire enquired about functional activities limited [26-28]. Prior to use, the questionnaire was assessed for logical validity by five (5) experts as described elsewhere [26]. The questionnaire yielded excellent Scale/Average Content Validity Index $(\mathrm{S}-\mathrm{CVI} / \mathrm{Ave}=0.97)[29,30]$. The questionnaire was evaluated for reproducibility among 16 occupational therapy students and showed kappa coefficients between 0.4 and 1 , indicating fair to perfect agreement assessments [31].

\section{Procedure}

This study adhered to ethical principles under the Declaration of Helsinki [32]. Ethical clearance was obtained from the Joint Research Ethics Committee for the UZCHS and Parirenyatwa Group of Health Sciences (JREC REF: 281/6) and Medical Research Council of Zimbabwe (MRCZ/B/1213). Data were collected in February 2017. Consenting participants firstly signed informed consent before completing the self-administered questionnaire.

\section{Statistical analyses}

The Shapiro-Wilk test assessed normality of continuous variables. Participants' demographic and universityrelated information were analysed using descriptive statistics. Mann-Whitney U test assessed for differences in participants ages by gender. The intensity of recurrent NSLBP was evaluated using Visual Analogue Scale (VAS). The independent $t$ test assessed for significant differences in the mean pain intensity between the sexes. Chi square test evaluated for an association between NSLBP and gender, age of the participants, place of residence and level of study $(\mathrm{p} \leq 0.05)$. Data were analysed using Statistica version 13.2.

\section{Results}

Of the 92 students, 90 (97.8\%) responded and had a median age of 22.0 years (Interquartile range, $\mathrm{IQR}=21-22$ years). The final sample had $61(67.8 \%)$ females. Males were significantly older compared to females $(\mathrm{U}=581, \mathrm{p}=0.009)$. Most participants stayed in UZ halls of residences $(n=52,57.8 \%)$. There were an almost equal number of third year students as there were fourth year students (Table 1). The lifetime prevalence of NSLBP was $56.7 \%(n=51)$. The mean age of onset of NSLBP was $19.7(\mathrm{SD}=1.64)$ years with no significant differences between sexes [ $\mathrm{t}(49)=1.63, \mathrm{p}=0.11$ ] Lifetime prevalence was associated with residing in UZ residences $\left[\mathrm{X}^{2}(1)=7.92, \mathrm{p}=0.005\right]$ but not with gender $\left[\mathrm{X}^{2}(1)=0.43, \mathrm{p}=0.51\right]$, and year of study $\left[\mathrm{X}^{2}(3)=2.06\right.$, $\mathrm{p}=0.56]$.

The 12-month prevalence of recurrent NSLBP was $38.9 \%(n=35)$. Of the $35,20(57.1 \%)$ experienced at least three episodes of recurrent NSLBP in the last 12 months. Each episode lasted 1-7 days in most participants $(\mathrm{n}=31,88.6 \%)$. The mean intensity of recurrent NSLBP episodes was $3.37(\mathrm{SD}=1.43)$ on the Visual Analogue Scale (VAS) with no significant difference between sexes $[\mathrm{t}(33)=0.04, \mathrm{p}=0.96]$. Only $7(20 \%)$ experienced at least one functional limitation in activities due to recurrent 
Table 1 Recurrent non-specific low back pain and socio-demographic associated factors $(\mathbf{N}=90)$

\begin{tabular}{|c|c|c|c|c|c|}
\hline Characteristics & Frequency, $n$ & LBP n (\%) & No LBP n (\%) & Chi square & $P$ value \\
\hline \multicolumn{6}{|l|}{ Gender } \\
\hline Male & 29 & $13(44.8)$ & $16(55.2)$ & \multirow[t]{2}{*}{$X^{2}(1)=0.63$} & \multirow[t]{2}{*}{0.43} \\
\hline Female & 61 & $22(36.1)$ & $39(63.9)$ & & \\
\hline \multicolumn{6}{|l|}{ Age (years) } \\
\hline 19 & 3 & $1(33.3)$ & $2(66.7)$ & \multirow[t]{7}{*}{$X_{\text {(linear trend) }}^{2}=8.38$} & \multirow[t]{7}{*}{0.21} \\
\hline 20 & 17 & $3(17.6)$ & $14(82.4)$ & & \\
\hline 21 & 17 & $8(47.1)$ & $9(52.9)$ & & \\
\hline 22 & 33 & $13(39.4)$ & $20(60.6)$ & & \\
\hline 23 & 11 & $5(45.5)$ & $6(54.5)$ & & \\
\hline 24 & 8 & $5(62.5)$ & $3(37.5)$ & & \\
\hline 25 & 1 & $0(0)$ & $1(100)$ & & \\
\hline \multicolumn{6}{|l|}{ Year of study } \\
\hline First year & 21 & $5(23.8)$ & $16(76.2)$ & \multirow[t]{4}{*}{$X^{2}(3)=2.03$} & \multirow[t]{4}{*}{0.57} \\
\hline Second year & 14 & $6(42.9)$ & $8(57.1)$ & & \\
\hline Third year & 28 & $11(39.3)$ & $17(60.7)$ & & \\
\hline Fourth year & 27 & $13(48.1)$ & $14(51.9)$ & & \\
\hline \multicolumn{6}{|l|}{ Place of residence } \\
\hline UZ residence & 52 & $26(50.0)$ & $26(50.0)$ & \multirow[t]{2}{*}{$X^{2}(1)=6.40$} & \multirow[t]{2}{*}{0.01} \\
\hline Outside UZ residence & 38 & $9(23.7)$ & $29(76.3)$ & & \\
\hline
\end{tabular}

UZ University of Zimbabwe

NSLBP. Additionally, 2 (5.7\%) students sought medical treatment for the pain and $6(17.1 \%)$ reported absenteeism from the university at one point in time due to recurrent NSLBP. Recurrent NSLBP was neither associated with gender nor year of study but was associated with lifetime NSLBP $\left[\mathrm{X}^{2}(1)=43.8, \mathrm{p}<0.01\right]$ and place of residence $\left[X^{2}(1)=6.40, p=0.01\right]$ (Table 1). Students residing at UZ reported more recurrent NSLBP. Although the 12 -month prevalence increased with age, this was not statistically significant $\left[\mathrm{X}_{\text {(linear trend) }}^{2}=8.38, \mathrm{p}=0.21\right]$.

\section{Discussion}

Although NSLBP is a common occurrence among undergraduate physiotherapy students worldwide $[7,10,12$, 17], nothing is known about the prevalence, clinical characteristics and consequences of the condition in the Zimbabwean setting. Similar studies in Zimbabwe investigated the burden of work-related musculoskeletal disorders (WMSDs) among qualified physiotherapists $[15,18]$. Results from these studies cited NSLBP as the most common occupational injury experienced especially by young qualified physiotherapists. This concurs with the present study as more than half (56.7\%) of the students reported having experienced at least one episode of NSLBP in their lifetime. This finding indicates that NSLBP is a common occurrence among Zimbabwean physiotherapy students. Studies elsewhere have reported comparable and contrasting findings $[7,11,12,17,33]$. Consistently, Horrell et al. [17] reported lifetime prevalence of $62.3 \%$ among physiotherapy students at one university in England. NSLBP was less common among South African undergraduate physiotherapy students with lifetime prevalence of $36 \%$ [7]. Additionally, physiotherapy students in Brazil were highly affected with $82.3 \%$ lifetime prevalence [11]. It appears that the variations in the lifetime prevalence figures between studies mainly reflect population and methodological differences [7].

In our study, the mean age of onset for an episode of NSLBP was 19.7 years implying that most students experienced their first episode of NSLBP soon after enrolling for physiotherapy. This finding suggests that studying physiotherapy is a potential risk factor for the development of NSLBP. This warrants longitudinal investigation into the factors associated with the occurrence of NSLBP among Zimbabwean undergraduate physiotherapy students. Elsewhere, the development of NSLBP among physiotherapy students has been linked with cumulative hours of practical exposure and demographic factors such as gender [7, 11]. Practical work in physiotherapy often involves use of physical manual techniques with performance of repetitive movements, prolonged standing, lifting, transferring and adoption of awkward postures [10]. Constant exposure coupled with inherent biological or gender differences probably account for the reported link between practical exposure, gender and NSLBP. However, in the present study, lifetime 
prevalence was not associated with gender $(\mathrm{p}=0.51)$ and year of study $(p=0.56)$. This possibly highlights the indiscriminate nature of NSLBP equally affecting both sexes and all students at different levels of study and these findings are consistent with other studies [10].

A small subset of undergraduate physiotherapy students (38.9\%) reported recurrent NSLBP in the last 12 months. This finding adds support to the fact that NSLBP is recurrent [25]. Recurrence rate of NSLBP among physiotherapy students was slightly higher compared to rates reported in other occupational groups in Zimbabwe. For instance, NSLBP was found to be recurrent in $30.7 \%$ of Zimbabwean high school-children [34]. Although these studies are incomparable because of different target population, the results of the present study potentially suggest greater exposure to occupational risk factors for NSLBP in physiotherapy students. Recurrent NSLBP may indeed be a problem among Zimbabwe undergraduate physiotherapy students considering also the reported 12-month prevalence of occupational NSLBP reported in qualified physiotherapists in the country. For example, Useh et al. [15] reported a comparable prevalence of $52.1 \%$ for LBP. There are few studies documenting the 12-month prevalence of NSLBP among undergraduate physiotherapy students and the prevalence figures have been shown to vary [10, 12, 13, 33]. Consistent with present study findings, Vincent-Onabajo et al. [10] reported a 12-month cross-sectional prevalence of $32.5 \%$ among Nigerian physiotherapy students. Other studies from Brazil and Pakistan reported relatively higher prevalence values above $70 \%[11,33]$.

The present study found that more than half of the students had at least three episodes of NSLBP in the last 12 months. Although the episodes were frequent, most were mild in intensity and lasted only for a short duration. These findings are interesting and suggest a favourable natural trajectory of NSLBP in young adults. Additionally, these finding highlight the benign nature of NSLBP experienced by physiotherapy students and similar outcomes have been reported in school-children [6]. However, the fact that the episodes were frequent shows possible constant exposure of the students to occupational risk factors associated with continued development of NSLBP. All these results possibly explain reduced school absenteeism rates among students who had recurrent NSLBP. Additionally, it is possible that the benign nature of the recurrent NSLBP account for reduced seeking medical professional help among the students $(\mathrm{n}=2$, $5.7 \%)$.

In conclusion, this present study showed that NSLBP is a common occurrence among undergraduate physiotherapy students at the UZ and in a small subset of students the condition is recurrent. Fortunately, the condition seems benign in nature with limited consequences on students.

\section{Limitations}

This study had the following limitations

i. The study was conducted as a cross-sectional study relying on self-reported data. Therefore, causality cannot be established between the factors identified to be associated with NSLBP.

ii. Recall bias and forward telescoping may have led to under-or-over-estimation of the prevalence figures [35].

iii. Data collection was conducted by the second author (KJC) who was a final undergraduate physiotherapy student at the time. The questionnaires were self-administered and questionnaires were collected immediately upon completion. Possibly, this could have influenced the results.

\section{Abbreviations}

IQR: interquartile range; LBP: low back pain; NSLBP: non-specific low back pain; SD: standard deviation; WMSDs: work-related musculoskeletal disorders; VAS: Visual Analogue Scale; UZCHS: University of Zimbabwe College of Health Sciences.

\section{Authors' contributions}

$\mathrm{MC}$ and KJC originally developed the concept and design of the study in consultation with JMD. KJC did the literature review and submitted the proposal draft for ethical approval to local institutional review boards. KJC conducted the data collection. MC drafted the manuscript with the assistance from JMD and MC acted as the corresponding author of the present study. MC and JMD performed all the statistical analysis and interpretation of study results. JMD performed the critical revision of the manuscript for intellectual content in preparation for submission to the journal. All authors read and approved the final manuscript.

\section{Author details}

${ }^{1}$ Department of Rehabilitation, College of Health Sciences, University of Zimbabwe, Ground Floor, New Health Sciences Building, Avondale, Harare, Zimbabwe. ${ }^{2}$ Mutare Provincial Hospital, P.O Box 30, Mutare, Harare, Zimbabwe.

\section{Acknowledgements}

The authors would like to thank all members of staff in the Rehabilitation Department at the College of Health Sciences, University of Zimbabwe for the support. Additional acknowledgements are extended to the panel of content experts who duly assisted with the content validation of the questionnaire prior to main study data collection. Lastly, the first author acknowledges the mentoring and research training received from University of Zimbabwe College of Health Sciences PERFECT (Promoting Excellence in Research and Faculty Enhanced Career Training) programme where he is a cohort 2 fellow until April 2019. PERFECT programme is supported by the Fogarty International Center of the National Institutes of Health under Award Number D43TW010137.

\section{Competing interests}

The authors declare that they have no competing interests. 


\section{Availability of data and materials}

The datasets generated and/or analysed during the current study are not publicly available due to the fact that the data is part of ongoing research. However, the data are available from the corresponding author on reasonable request.

\section{Consent for publication}

Not applicable as the manuscript does not contain any data from any individual person

\section{Ethics approval and consent to participate}

This study adhered to ethical principles under the Declaration of Helsinki. Ethical clearance was sought and obtained from the Joint Research Ethics Committee for the University of Zimbabwe, College of Health Sciences and Parirenyatwa Group of Health Sciences (JREC REF: 281/6) and Medical Research Council of Zimbabwe (MRCZ/B/1213). Written informed consent was obtained from the participants prior to questionnaire administration. In addition, participants were allowed to withdraw from the study at any time without any consequences to them.

\section{Funding}

None.

\section{Publisher's Note}

Springer Nature remains neutral with regard to jurisdictional claims in published maps and institutional affiliations.

Received: 10 July 2018 Accepted: 27 September 2018

Published online: 04 October 2018

\section{References}

1. Houghton KM. Review for the generalist: evaluation of low back pain in children and adolescents. Paediatr Rheumatol. 2010;8:28

2. Taspinar F, Taspinar B, Cavlak U, Celik E. Determining the Pain-affecting factors of university students with non-specific low back pain. J Phys Ther Sci. 2013;25(12):1561-4

3. Smith DR, Leggat PA. Back pain in the young: a review of studies conducted among school-children and university students. Curr Pediatr Rev. 2007;3:69-77

4. Louw QA, Morris LD, Grimmer-Somers K. The prevalence of low back pain in Africa: a systematic review. BMC Musculoskelet Disord. 2007:8:1-14

5. Brennan G, Shafat A, Donncha MC, Vekins C. Lower back pain in physically demanding college academic programs: a questionnaire based study. BMC Musculoskelet Disord. 2007:8:67.

6. Chiwaridzo M, Naidoo N. Prevalence and associated characteristics of recurrent non-specific low back pain in Zimbabwean adolescents: a cross-sectional study. BMC Musculoskelet Disord. 2014;15:381.

7. Burger E, Myezwa H, Naidoo V, Olivier B, Rothberg A. Low back pain in physiotherapy students: prevalence and the association with neuromuscular findings. South Afr J Physiother. 2013;69(4):29-35.

8. Hafeez K, Ahmed Memon A, Jawaid M, Usman S, Usman S, Haroon S. Back pain-are health care undergraduates at risk? Iran J Public Health. 2013;4(28):819-25.

9. Mierzejewski M, Kumar S. Prevalence of low back pain among physica therapists in Edmonton, Canada. Disabil Rehabil. 1997;19:309-17.

10. Vincent-Onabajo GO, Nweze E, Gujba FK, Matsa MA, Ali MU, et al. Prevalence of low back pain among undergraduate physiotherapy students in Nigeria. Pain Res Treat. 2016;2:1-4

11. Falavigna A, Teles AR, Mazzocchin T, De Braga GL, Kleber FD, Barreto $F$, et al. Increased prevalence of low back pain among physiotherapy students compared to medical students. Eur Spine J. 2011;20:500-5.

12. Nyland $\sqcup$, Grimmer KA. Is undergraduate physiotherapy study a risk factor for low back pain? A prevalence study of LBP in physiotherapy students. BMC Musculoskelet Disord. 2003;4:22

13. Bharadva NA, Verma MR, Kantharia SL. Are physiotherapy students at risk of musculoskeletal pain? A study on physiotherapy students of government physiotherapy college, New Civil Hospital, Surat. IJIMS. 2014:1(8):157-63.
14. West DJ, Gardner D. Occupational injuries of physiotherapists in North and Central Queensland. Aust J Physiother. 2001;47(3):179-86.

15. Useh U, Igumbor EU, Madzivire DM. Occupational injuries among physiotherapists: a case study in Zimbabwe. Afr Safety Promot. 2002;1 (2):26-33.

16. Nordin NAM, Leonard JH, Thye NC. Work-related injuries among physiotherapists in public hospitals-a Southeast Asian picture. Clinics. 2011:66(3):373-8.

17. Horrell KJ, Wreford-Brown AJ, Harwood S, Freeman JA. The prevalence of low back pain in under-graduate students with different educational exposures. Physiother Pract Res. 2010;31(1):41-6.

18. Pfumojena $C$. The prevalence and nature of work related musculoskeletal disorders amongst physiotherapists in Zimbabwe. 2016. M.Sc. Thesis. University of Witwatersrand. http://wiredspace.wits.ac.za/jspui/bitst ream/10539/19746/1/Final\%20submission\%20Research\%20report-Chido $\% 20$ Pfumojena(760648)-The\%20prevalence\%20and\%20nature\%20 of\%20 work\%20related\%20musculoskeletal\%20disorders\%20amongst\%20phy siotherapist.pdf. Accessed 10 July 2018.

19. O'Sullivan PB, Beales DJ, Smith AJ, Straker LM. Low back pain in 17 year olds has a substantial impact and represents an important public health disorder: a cross-sectional study. BMC Public Health. 2012:12:100.

20. Imdad F, Ishaque F, Yasmeen S, Lal W, Sheikh SA, Nawaz U, et al. Prevalence of low back pain among the undergraduate students of Isra University Karachi campus. Int J Physiother. 2016;31(1):119-23.

21. Munambah N, Chiwaridzo M, Mapingure T. A cross-sectional study investigating impressions and opinions of medical rehabilitation professionals on the effectiveness of the Ponseti method for treatment of clubfoot in Harare, Zimbabwe. Arch Physiother. 2016;6:7.

22. Rannisto S, Okuloff A, Uitti J, Paananen M, Rannisto PH. Malmivaara. Leglength discrepancy is associated with low back pain among those who must stand while working. BMC Musculoskeletal Disord. 2015;16:110.

23. Chiwaridzo M, Naidoo N. Are parents and adolescents in agreement on reporting of recurrent NSLBP in adolescents? A cross-sectional descriptive study. BMC Pediatr. 2015;15:203.

24. Chiwaridzo M, Chikasha TN, Naidoo N, Dambi JM, Tadyanemhandu C, Munambah N, Chizanga PT. Content validity and test-retest reliability of a low back pain questionnaire in Zimbabwean adolescents. Arch Physiother. 2017;7:3

25. Stanton TR, Latimer J, Maher CG, Hancock MJ. A modified Delphi approach to standardise low back pain recurrence terminology. Eur Spine J. 2011:14:744-52

26. Chiwaridzo M, Naidoo N. Functional consequences and health-care seeking behaviour for recurrent NSLBP in Zimbabwean adolescents: a cross-sectional study. Eur Spine J. 2016;25:643-50.

27. Watson K, Papageorgiou AC, Jones GT, Taylor S, Symmons DP, Silman AJ, et al. Low back pain in schoolchildren: occurrence and characteristics. Pain. 2002;97:87-92.

28. Jones GT, Macfarlane GJ. Predicting persistent low back pain in schoolchildren: a prospective cohort study. Arthritis Rheum (Arthritis Care Res). 2009:61:1359-66.

29. Davis LL. Instrument review: getting the most from your panel of experts. Appl Nurs Res. 1992:4(5):194-7.

30. Polit DF, Beck CT, Owen SV. Is the CVI an acceptable indicator of content validity? Appraisal and recommendations. Res Nurs Health. 2007;30(4):459-67.

31. Landis JR, Koch GG. The measurement of observer agreement for categorical data. Biometrics. 1977;33:159-74.

32. World Health Organisation. Bull World Health Organ. 2001;79(4):373-4.

33. Arsh A, Jan A. Prevalence of low back pain among DPT students in Peshawar. SAJMED. 2016;1(2):29-34.

34. Chiwaridzo M, Chiwah RV, Dambi JM, Matare T. Recurrent non-specific low back pain: a Cross-sectional survey on prevalence, nature of recurrent episodes and the role of physical activity and psychological status in high school adolescents in Harare, Zimbabwe. Ann Paediatr Rheumatol. 2015:4:63-9.

35. Milanese S, Grimmer-Somers K. What is adolescent low back pain? Current definitions used to define the adolescent with low back pain. J Pain Res. 2010:3:57-66. 